\title{
Kidney Medullary Carcinoma
}

National Cancer Institute

\section{Source}

National Cancer Institute. Kidney Medullary Carcinoma. NCI Thesaurus. Code C7572.

A type of renal carcinoma affecting mostly young African-Americans. It is located in the medulla of the kidney, and follows an aggressive clinical course. Most reported cases have shown metastatic disease at the time of diagnosis. 